\title{
Effects of gender and diet on back fat and loin area ultrasound measurements during the growth and final stage of fattening in Iberian pigs
}

\author{
Ana González ${ }^{1}$, Dolores Ayuso ${ }^{2}$, Francisco Peña ${ }^{1}$, Andrés L. Martínez ${ }^{1}$, and Mercedes Izquierdo ${ }^{2}$ \\ ${ }^{1}$ Department of Animal Production, University of Córdoba, Córdoba, Spain \\ ${ }^{2}$ Departament of Animal Production, CICYTEX, Badajoz, Spain \\ Correspondence to: Ana González (v32gomaa@uco.es)
}

Received: 13 October 2016 - Revised: 30 May 2017 - Accepted: 13 June 2017 - Published: 20 July 2017

\begin{abstract}
Reared in extensive parcels, 50 castrated or spayed Iberian pigs were fattened with conventional or high-oleic-concentrate diets to evaluate the effect of diet and sex on the measurements of the loin area depth, back fat thickness and its layers during the last 6 months before slaughter at eight time points in two anatomical locations by serial scans. The scan was the factor that had the greatest influence, followed by sex and diet. Back fat thickness at 10th rib level was higher than at 14th rib level. The thickness of the outer, middle and inner layers progressively increased over the study period. Throughout the experimental period, the differences between two successive scans of the M. longissimus area did not differ significantly, obtaining the lowest value at the third scan and the highest at the fifth scan. The ultrasound back fat depth was affected by sex, being greater in females and in animals with a high-oleic diet. Positive significant correlations were observed for measurements assessed. The $R^{2}$ values for the regression equations to estimate M. longissimus area were lower than the values found for the prediction of fat measurements, and they differed between sex and diet. The relative back fat growth was higher than M. longissimus area, not permitting the establishment of a similar growth pattern for fat and muscle. The sex and diet was taken into account in the predictive models. The subcutaneous adipose layers in Iberian pigs grow at different rates during the last 6 months before slaughter; with the ultrasound serial scan, it is possible to show these changes. The change in diet and the sex affect the adipose tissue development, being more noticeable in the middle layer of back fat at 10th rib level and the inner layer at 14th rib level. However, the sex and the use of an enriched oleic acid diet do not affect to loin development. As the middle layer of back fat shows more growth, this layer could be the best to be included in predictive models. The middle layer of back fat could also be good to be included in predictive models. Back fat thickness at the eighth scan can be predicted with moderate accuracy from corresponding measurements taken 30 days earlier and with less accuracy as the interval between measurements increases.
\end{abstract}

\section{Introduction}

The autochthonous Iberian pig breed is traditionally bred in southwestern Spain and has a specific conformation and high adipogenetic potential, influenced by a diet based on grass and acorns. This pig breed is reared under different conditions, all of which are regulated by the Spanish Ministry of Agriculture (BOE, 2014) according to the features of the last fattening phase: intensive system, Recebo, Cebo a campo and Montanera.
In the last decades the pork industry has found features to improve meat quality. In this sense, the main trait of Iberian pig meat is its high content of intramuscular fat, which is desirable in obtaining dry-cured products (mainly ham, foreleg and loin) and important for flavour and to provide slow dehydration during the curing process (Fernandez et al., 2003). According to Lopez-Bote (1998), in the last phase of fattening (around $150 \mathrm{~kg}$ of body weight) the Iberian pig can reach $60 \%$ carcass fat, $15 \mathrm{~cm}$ of back fat depth and $10-13 \%$ intramuscular fat content. Factors such as diet or sex are the most 
investigated in Iberian pig production, with the purpose of improving intramuscular fat content (Ayuso et al., 2004).

Back fat layer thickness is an important parameter at all stages of pig production. It is used as a tool for the evaluation of dietary requirements in order to optimize growth and determine the price (McEvoy et al., 2007). Measurements of thickness of subcutaneous adipose tissue are useful for monitoring the production process in order to optimize growth and carcass composition. These measurements can be obtained using ultrasound techniques, the use of which has become widespread for the Iberian pig in recent decades either for descriptive studies or to predict carcass composition (Ayuso et al., 2013). Likewise, these measurements can be very useful in improving the response of genetic selection in economic traits (Moeller et al., 1998). It has been proved that back fat thickness, loin area and intramuscular fat content are good features to predict pig carcass characteristics (Ayuso et al., 2014).

The goal of this study was to evaluate, under outdoor intensive conditions, the effect of diet and sex on the measurements of the loin area depth, back fat thickness and its layers at eight time points in two anatomical locations by serial scans before and during the final fattening phase in Iberian pigs.

\section{Material and methods}

\subsection{Animal management and experimental design}

The experimental procedures used in this study were in compliance with the Spanish guidelines for the care and use of animals in research (BOE, 2007). The data were collected from 50 castrated or spayed Iberian pigs ( 25 males and $25 \mathrm{fe-}$ males). Pigs in the study were progeny from Iberian purebred sires and dams. The trial was conducted at Valdesequera Farm, a central Iberian swine test station (Badajoz, Spain). From 15 days of age to weaning (42-49 days old), piglets had free access to a commercial pre-starter feed. At weaning, all piglets were moved to an open-air fenced-in area where they had full access to feed and water. The pigs were reared in extensive parcels according to the Spanish legislation (BOE, 2007), without the presence of oaks to avoid the intake of acorns, and they received the same standard diet based on commercial concentrate feed. A gradual change from a starter diet ( $\sim 23 \mathrm{~kg}$ live weight) to subsequently receiving a growth diet ( $\sim 70 \mathrm{~kg}$ live weight) occurred. At the beginning of the fattening period ( $\sim 90 \mathrm{~kg}$ live weight), the males were castrated and the females were ovariectomized under anesthesia following the Spanish regulations. Then pigs of the same sex were sorted by weight into eight pens of 3-4 pigs each and were then randomly assigned to one of two dietary treatments: conventional concentrate feed (C) or concentrate diet containing a high level of oleic acid (HO). The pens had similar characteristics. The chemical composi-
Table 1. The chemical composition of dietary ingredients.

\begin{tabular}{lrr}
\hline Analysed composition $^{\mathrm{a}}$ & Concentrate $^{\mathrm{b}}$ & Concentrate high oleic $^{\mathrm{b}}$ \\
\hline Crude protein \% & 16.10 & 15.00 \\
Crude fat \% & 2.44 & 5.66 \\
Crude fibre \% & 3.99 & 5.07 \\
Ash \% & 5.80 & 5.10 \\
Oleic \% & 0.54 & 3.30 \\
\hline
\end{tabular}

${ }^{\mathrm{a}}$ Expressed as percentage of dry matter. ${ }^{\mathrm{b}}$ By formulation.

tion of each feed is presented in Table 1 . The diet was offered ad libitum.

\subsection{Ultrasound measurements}

The pigs were weighed and ultrasonically scanned throughout the fattening period. To obtain the ultrasound images, pigs were immobilized and restrained by the head in a squeeze chute and the image sites were determined by physical palpation to accurately ascertain the scanning sites. The animals were held manually, avoiding any abnormal situation that could stress the animal, and they were only scanned in a relaxed posture, permitting accurate measurements. A mix of Eco Gel and isopropyl alcohol was used as a sound conducting material to allow a better acoustic contact surface between the probe and the skin. An Aloka 500V real-time ultrasound machine (Aloka Holding Europe, Switzerland) equipped with a $12.5 \mathrm{~cm}, 3.5 \mathrm{MHz}$ linear array transducer (Aloka Holding Europe, Switzerland) was used. The adjust gain settings were 90 for overall gain, -25 for near gain and 2.1 for far gain. The focus zones were 1 and 2 on the Aloka $500 \mathrm{~V}$ for all images collected. Captured ultrasonic images were recorded and interpreted later with Biosoft ${ }^{\circledR}$ software (Biotronics Inc., Ames, IA, USA). Ultrasound images for measurement were taken along the dorsal midline at 10th and 14th rib projection with the transducer centred perpendicularly at the anatomical site. A cross-sectional image of the loin area and back fat thickness and its layers (outer, middle and inner) on the right side of the pig at the 10th intercostal space and just behind the last rib (14th rib) were obtained using an ultrasound stand-off guide (Superflab ${ }^{\circledR}$ ) mounted on the linear probe and conforming to the curvature of the pig's back and ham. Images were digitalized and stored in a computer for later analysis with Biosoft ${ }^{\circledR}$ software (Biotronics Inc., Ames, IA, USA). Determination of the anatomical location of the 10th and 14th ribs was made based on presence of muscle systems viewed on the ultrasound image. Back fat thickness was measured at a midline of the distance along the loin muscle area from skin with a perpendicular line to skin. The loin area was measured to draw the outline around the loin muscle. 


\subsection{Statistical analyses}

All the statistical analyses were performed using SAS 9.3 (SAS Institute Inc., Cary, NC). Since the study included repeated measurements (serial ultrasound scanning), the mixed procedure assuming non-equal covariances among serial samples was used to compare the eight serial ultrasound scanning measurements of the different traits (back fat thickness and loin area at the 10th and 14th rib levels). The model included sex, feed and scan as fixed effects and body weight as a covariate. Ultrasound scan was included as a repeated measurement in the repeated statement of the mixed procedures. Several interactions were also included in the model. The least significant difference test was used to compare least squares means. Correlations between the ultrasound measurements at 10th rib level and the same ultrasound measurements at 14th rib level were investigated in the fourth to seventh scans. Similarly, total back fat thickness and loin area regression coefficients relating the ultrasound measurements at the eighth scan and corresponding measurements at the previous scan were obtained too.

The allometric equation was used for the depiction of differential growth of muscle and fatty tissue. This model describes a part-to-whole relationship and has the following form:

$\log Y=\log a+b \times \log X$,

where is the intercept on the $Y$ axis, $b$ is the allometric growth coefficient (slope), $X$ is the body weight, and $Y$ is the total back fat thickness and its layers or loin area.

The allometric coefficients were $t$ tested to determine if the allometric coefficient defined a fast, slow or equivalent pattern of growth. The $t$ tests were computed as $t=$ $(b-\mathrm{Bo}) / \mathrm{SEb}$, which distributes as Student's $t$.

\section{Results}

Least square means ( \pm standard errors) of the ultrasound measurements are listed in Table 2. As expected, the scan was the factor that had the greatest influence, followed by sex and diet.

Table 3 shows the least squares means ( \pm standard errors) for the body weight, back fat thickness and M. longissimus area at the 10th and 14th rib levels. Table 3 also shows the thickness of individual back fat layers: outer, middle and inner. The live weight ranged from $65.6 \pm 1.5 \mathrm{~kg}$ at the start to $161.6 \pm 1.4 \mathrm{~kg}$ at the end of the experimental period. This represents an increase of $96.0 \mathrm{~kg}$ and an average daily gain of $458 \mathrm{~g} \mathrm{day}^{-1}$ (360 and $720 \mathrm{~g} \mathrm{day}^{-1}$ at the start and end of the trial, respectively). Increases in the ultrasound measurements with increased body weight were expected. BF10 and BF14 (see underneath Table 2 for an explanation of abbreviations) increased significantly $(p<0.05)$ during the studied period. In all scans, back fat thickness at 10th rib level was higher than that recorded at 14th rib level, although this relationship changed significantly $(p<0.05)$ as body weight increased (1.97 and $1.28 \mathrm{~mm}$ in the first and last scans, respectively) as a result of higher back fat growth at 14th rib level (152.8 vs. $1225.5 \%$ ). The thickness of the outer, middle and inner layers progressively increased over the period of study, representing $152.80,115.8,119.4,135.3,184.0$ and $135.9 \%$ of the initial value for BFO10, BFM10, BFI10, BFO14, BFM14 and BFI14, respectively. The greatest increase occurred at the 14th rib level. Regarding the back fat layers, the middle and outer layers showed the highest and lowest growth, respectively. In the data set, the outer, middle and inner layers of the fat represented 20.33, 55.28 and $24.73 \%$ at 10th rib level and 22.97, 46.10 and $32.22 \%$ at 14th rib level. As a proportion of the total back fat depth, a decrease appeared in $\mathrm{BFO} 10$ (from 57.05 to $53.94 \%$ ), BFO14 (from 23.43 to $20.76 \%$ ) and BFI14 (from 34.42 to $30.62 \%$ ), and an increase in BFM10 (from 52.88 to $56.68 \%$ ) and BFM14 (from 41.49 to $49.97 \%$ ), while BFI10 was relatively static over the time period (from 25.20 to $24.60 \%$ ).

The change in back fat thickness per unit of body weight was 0.456 and $0.308 \mathrm{~mm} \mathrm{~kg}^{-1}$ for BF10 and BF14, respectively, recording the highest values in the first scan $(0.635$ and $0.390 \mathrm{~mm} \mathrm{~kg}^{-1}$, respectively). Similarly, to what was observed for back fat thickness, the M. longissimus area at 10th rib level was higher than at 14 th rib level. The differences in the M. longissimus area between two successive scans are not significant $(p>0.05)$ throughout the experimental period, recording the lowest value $\left(0.04\right.$ and $0.92 \mathrm{~cm}^{2}$ for 10th and 14th levels, respectively) for the fourth scan and the highest for the first scan $\left(1.41 \mathrm{~cm}^{2}\right)$. The M. longissimus area at both levels increased throughout the study period, representing $138.6 \%$ for LA10 at the last scan and $123.6 \%$ for LA14 at the first scan. The M. longissimus area per kilogram of body weight ratio decreased significantly as body weight increased: from 0.223 to $0.126 \mathrm{~mm} \mathrm{~kg}^{-1}$ for LA10 and from 0.209 to $0.105 \mathrm{~mm} \mathrm{~kg}^{-1}$ for LA14 for the first and last scans, respectively.

The least squares means for the ultrasound measurements by sex are showed in Figs. 1 and 2. Sex did not significantly affect $(p>0.05)$ the body weight gain $(95.7$ and $96.2 \mathrm{~kg}$ in males and females, respectively) for the entire study period. All ultrasound measurements increased significantly as body weight increased, although at different rates. The back fat depth and rate of back fat growth were affected by sex $(p<0.05)$. The ultrasound back fat depth was greater in females, although the rates of back fat depth growth in the males were lower than those recorded in females (118.46 and $124.18 \%$ for BF10 and 149.21 and $152.0 \%$ for BF14 in males and females, respectively). The back fat thickness had higher growth in females $(138.09 \%)$ than the M. longissimus area (135.19\%); in males the opposite occurred (133.83 vs. $127.45 \%$, back fat thickness (BF) and M. longissimus area (LA), respectively). Also, it has been noted that the increase in back fat thickness was higher at 14th rib level, which caused the BF10/BF14 ratio to de- 
Table 2. Least squares means $( \pm \mathrm{SE})$ for the data set of ultrasound traits studied by sex and feed and analysis of variance test.

\begin{tabular}{|c|c|c|c|c|c|c|c|c|c|c|c|}
\hline & \multicolumn{2}{|c|}{ Sex } & \multicolumn{2}{|c|}{ Feed } & \multirow[b]{2}{*}{ Weight } & \multicolumn{6}{|c|}{ Effects } \\
\hline & Male & Female & $\mathrm{C}$ & $\mathrm{HO}$ & & Sex & Feed & Scan & Sex $\times$ feed & Feed $\times$ scan & Sex $\times$ scan \\
\hline $\mathrm{BF} 10(\mathrm{~mm})$ & $45.19 \pm 0.79$ & $47.67 \pm 0.86$ & $44.72 \pm 0.90$ & $48.14 \pm 0.84$ & $<0.0001$ & 0.0177 & 0.0101 & $<0.0001$ & 0.2421 & $<0.0001$ & 0.2701 \\
\hline $\mathrm{BFO} 10(\mathrm{~mm})$ & $9.21 \pm 0.20$ & $9.67 \pm 0.22$ & $9.25 \pm 0.25$ & $9.64 \pm 0.23$ & $<0.0001$ & 0.0325 & 0.3369 & $<0.0001$ & 0.2346 & 0.0060 & 0.3713 \\
\hline BFM10 (mm) & $24.08 \pm 0.56$ & $27.25 \pm 0.61$ & $24.75 \pm 0.64$ & $26.58 \pm 0.60$ & $<0.0001$ & 0.0045 & 0.0263 & $<0.0001$ & 0.0885 & $<0.0001$ & 0.0077 \\
\hline BFI10 (mm) & $11.08 \pm 0.25$ & $11.88 \pm 0.27$ & $11.12 \pm 0.30$ & $11.84 \pm 0.29$ & $<0.0001$ & 0.5469 & 0.0542 & 0.0841 & 0.0533 & 0.0010 & 0.0148 \\
\hline LA10 $\left(\mathrm{cm}^{2}\right)$ & $17.80 \pm 0.21$ & $18.06 \pm 0.23$ & $18.11 \pm 0.24$ & $17.76 \pm 0.22$ & 0.0067 & 0.2602 & 0.2209 & $<0.0001$ & 0.4333 & 0.0495 & 0.0001 \\
\hline $\mathrm{BF} 14(\mathrm{~mm})$ & $31.60 \pm 0.72$ & $32.36 \pm 0.75$ & $30.51 \pm 0.92$ & $33.44 \pm 0.88$ & $<0.0001$ & 0.0362 & 0.0608 & $<0.0001$ & 0.6659 & $<0.0001$ & 0.1668 \\
\hline $\mathrm{BFO} 14(\mathrm{~mm})$ & $7.25 \pm 0.20$ & $7.43 \pm 0.21$ & $7.22 \pm 0.24$ & $7.47 \pm 0.22$ & $<0.0001$ & 0.5736 & 0.4512 & $<0.0001$ & 0.0259 & 0.0670 & 0.2191 \\
\hline BFM14 (mm) & $14.25 \pm 0.43$ & $15.23 \pm 0.45$ & $14.17 \pm 0.55$ & $15.31 \pm 0.52$ & $<0.0001$ & 0.0258 & 0.2150 & $<0.0001$ & 0.3102 & 0.0001 & 0.6585 \\
\hline BFI14 (mm) & $10.23 \pm 0.30$ & $10.37 \pm 0.32$ & $9.63 \pm 0.37$ & $10.97 \pm 0.35$ & $<0.0001$ & 0.1164 & 0.0250 & $<0.0001$ & 0.1732 & 0.0263 & 0.4353 \\
\hline $\mathrm{LA} 14\left(\mathrm{~cm}^{2}\right)$ & $15.55 \pm 0.20$ & $16.03 \pm 0.22$ & $15.75 \pm 0.23$ & $15.83 \pm 0.22$ & $<0.0001$ & 0.0251 & 0.9739 & $<0.0001$ & 0.1482 & 0.5185 & 0.6610 \\
\hline
\end{tabular}

C: concentrated feed system; HO: high oleic system; BF10: ultrasonic back fat depth at 10th rib; BFO10: ultrasonic outer layer depth at 10th rib; BFM10: ultrasonic middle layer depth at 10th rib; BFI10: ultrasonic inner layer depth at 10th rib; LA10: M. longissimus area at 10th rib; BF14: ultrasonic back fat depth at 14th rib; BFO14: ultrasonic outer layer depth at 14th rib; BFM14: ultrasonic middle layer depth at 14th rib; BFI14: ultrasonic inner layer depth at 14th rib; LA14: M. longissimus area at 14th rib.

Table 3. Least square means $( \pm \mathrm{SE})$ for body weight, ultrasonic back fat depth and loin area in pigs of the Iberian breed.

\begin{tabular}{|c|c|c|c|c|c|c|c|c|}
\hline Scan & First & Second & Third & Fourth & Fifth & Sixth & Seventh & Eighth \\
\hline $\mathrm{N}$ & 50 & 50 & 50 & 50 & 50 & 50 & 50 & 50 \\
\hline $\mathrm{BW}$ & $59 \pm 1.54$ & $.05 \pm 1.58$ & $.27 \pm 1.52$ & $95.24 \pm 1.52$ & $110.78 \pm 1.48$ & $124.00 \pm 1.43$ & $139.91 \pm 1.43$ & $161.57 \pm 1.43$ \\
\hline $\mathrm{BF} 10(\mathrm{~mm})$ & $.63 \pm 1.73$ & $41.98 \pm 1.30$ & $43.90 \pm 1.00$ & $46.24 \pm 0.83$ & $47.46 \pm 0.79$ & $48.34 \pm 0.93$ & $50.89 \pm 1.36$ & \pm 2.02 \\
\hline $\mathrm{BFO} 10(\mathrm{~mm})$ & $7.08 \pm 0.43$ & $7.95 \pm 0.33$ & $8.80 \pm 0.27$ & $9.34 \pm 0.22$ & $10.01 \pm 0.21$ & $10.73 \pm 0.23$ & $10.86 \pm 0.36$ & $10.77 \pm 0.52$ \\
\hline BFM & $23.75 \pm 1.09$ & $23.66 \pm 0.83$ & $24.61 \pm 0.63$ & $26.17 \pm 0.52$ & $91 \pm 0.56$ & $26.23 \pm 0.58$ & $27.49 \pm 0.86$ & $50 \pm 1.24$ \\
\hline BFI & $10.50 \pm 0.54$ & $10.79 \pm 0.42$ & $11.02 \pm 0.32$ & $11.55 \pm 0.264$ & $=0.22$ & $7 \pm 0.32$ & $10 \pm 0.44$ & 0.72 \\
\hline & & & & & & & 0.40 & 0.63 \\
\hline $\mathrm{BF} 14$ (mm) & $25.59 \pm 1.38$ & $26.85 \pm 1.06$ & $28.39 \pm 0.89$ & $31.60 \pm 0.80$ & $32.77 \pm 0.86$ & $34.81 \pm 0.99$ & $36.71 \pm 1.28$ & $39.10 \pm 1.73$ \\
\hline BFO14 (mm) & $6.00 \pm 0.39$ & $6.33 \pm 0.29$ & $6.78 \pm 0.23$ & $7.51 \pm 0.22$ & $7.57 \pm 0.20$ & $8.14 \pm 0.24$ & $8.31 \pm 0.32$ & $8.12 \pm 0.47$ \\
\hline BFM14 (mm) & $10.62 \pm 0.79$ & $11.18 \pm 0.60$ & $12.24 \pm 0.48$ & $14.13 \pm 0.48$ & $15.22 \pm 0.53$ & $16.67 \pm 0.59$ & $18.33 \pm 0.77$ & $19.54 \pm 1.04$ \\
\hline BFI14 (mm) & $8.81 \pm 0.69$ & $9.43 \pm 0.52$ & $9.96 \pm 0.41$ & $10.63 \pm 0.37$ & $10.53 \pm 0.32$ & $10.31 \pm 0.37$ & $10.80 \pm 0.57$ & $11.97 \pm 0.89$ \\
\hline LA14 $\left(\mathrm{cm}^{2}\right)$ & $13.69 \pm 0.51$ & $14.56 \pm 0.37$ & $15.48 \pm 0.29$ & $16.28 \pm 0.24$ & $16.32 \pm 0.23$ & $16.45 \pm 0.24$ & $16.63 \pm 0.36$ & $16.92 \pm 0.55$ \\
\hline
\end{tabular}

BW: body weight; BF10: ultrasonic back fat depth at 10th rib; BFO10: ultrasonic outer layer depth at 10th rib; BFM10: ultrasonic middle layer depth at 10th rib; BFI10: ultrasonic inner layer depth at 10th rib; LA10: M. longissimus area at 10th rib; BF14: ultrasonic back fat depth at 14th rib; BFO14: ultrasonic outer layer depth at 14th rib; BFM14: ultrasonic middle layer depth at 14th rib; BFI14: ultrasonic inner layer depth at 14th rib; LA14: M. longissimus area at 14th rib.

crease from 1.63 and 1.61 for males and females, respectively, in the first control to 1.29 and 1.31 in the last scan. For M. longissimus area no significant difference $(P>0.05)$ between locations was found, with a LA10 / LA14 ratio of 1.07 in the first scan for both sexes and 1.23 and 1.16 in the last scan for males and females, respectively. No significant differences were observed in the percentages of each back fat layer and total thickness between the sexes $(54.15$ and $56.16 \%$ for BFO10, 20.20 and $20.48 \%$ for BFM10, 25.23 and $24.17 \%$ for BFI10, 23.68 and $22.28 \%$ for BFO14, 45.27 and $46.84 \%$ for BFM14, and 32.35 and $32.13 \%$ for BFI14 in males and females, respectively). The back fat layer growth was different in both sex and anatomy levels (143.06 and 152.66 for BFO10, 137.63 and 130.36 for BFO14, 108.35 and 122.44 for BFM10, 178.88 and 181.76 for BFM14, 126.43 and 116.81 for BFI10, and 130.88 and 135.89 for BFI14 in males and females, respectively.)The back fat thickness / body weight ratio increased as body weight increased, with females showing a higher increase ( 0.378 vs. $0.405 \mathrm{~mm} \mathrm{~kg}^{-1}$ for BF10 in males and 0.404 vs. $0.448 \mathrm{~mm} \mathrm{~kg}^{-1}$ in females, 0.195 vs. $0.316 \mathrm{~mm} \mathrm{~kg}^{-1}$ for BF14 in males and 0.206 vs. $0.350 \mathrm{~mm} \mathrm{~kg}^{-1}$ in fe- males). By contrast, the M. longissimus area / live weight ratio showed a significant $(p<0.05)$ decrease for LA10 in males and females $\left(0.194\right.$ vs. $0.137 \mathrm{~cm}^{2} \mathrm{~kg}^{-1}$ and $0.213 \mathrm{vs.}$ $0.134 \mathrm{~cm}^{2} \mathrm{~kg}^{-1}$, respectively) and LA14 in males $(0.167 \mathrm{vs}$. $0.121 \mathrm{~cm}^{2} \mathrm{~kg}^{-1}$ ) instead of an increase for LA14 in females $\left(0.182\right.$ vs. $\left.0.124 \mathrm{~cm}^{2} \mathrm{~kg}^{-1}\right)$. These results are in line with allometric coefficients that were obtained (Table 4).

The least squares means for the ultrasound measurements by diet are shown in Figs. 3 and 4 . The growth was affected $(p<0.05)$ by feeding system. Total weight gain of pigs on a $C$ ration was slightly lower $(91.6 \mathrm{vs.} 99.4 \mathrm{~kg})$ than that recorded in pigs on a $\mathrm{HO}$ ration. The back fat thickness increased more (110.25 and $133.44 \%$ for BF10, and 134.71 and $144.82 \%$ for BF14 in C and HO groups, respectively) than the M. longissimus area (139.74 and $124.83 \%$ for LA10, and 134.71 and $122.52 \%$ for LA14 in C and HO groups, respectively). The back fat layers showed a higher increase at 14th rib level than 10th rib level except for the outer layer in the $\mathrm{C}$ group. The layer with the lowest growth was the medium layer at 10th rib level (106.22 and $125.14 \%$ for $\mathrm{C}$ and $\mathrm{HO}$, respectively) and the inner layer for C (116.09\%) and the outer layer for $\mathrm{HO}$, both at 14th rib level. 

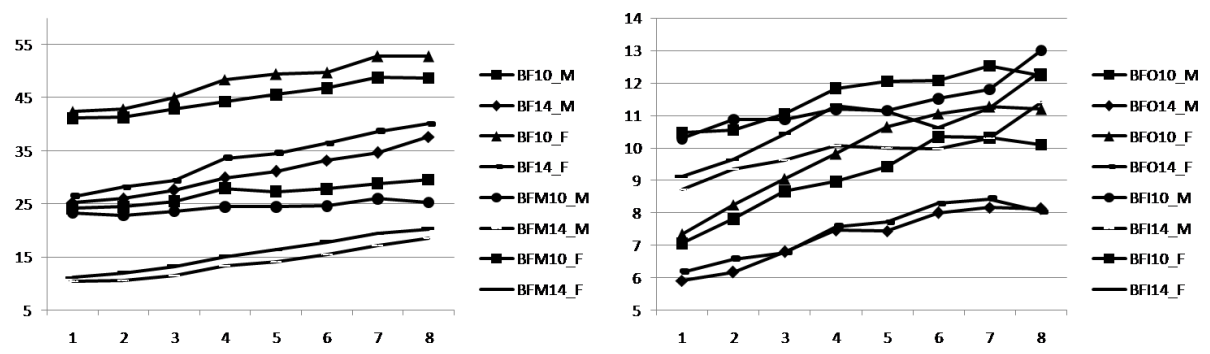

Figure 1. Changes in ultrasonic back fat depth and its layers as functions of scans in pigs of the Iberian breed.

Table 4. Allometric coefficients $\left(R^{2}\right)$ for ultrasonic back fat depth and loin area in pigs of the Iberian breed.

\begin{tabular}{lrrrrrr}
\hline & \multicolumn{3}{c}{ Scans 1 to 8} & Scans 1 to 4 & \multicolumn{2}{c}{ Scans 5 to 8 } \\
\cline { 2 - 3 } \cline { 7 - 7 } & & Males & Females & & C & HO \\
\hline BF10 & $1.09(0.88)$ & $1.08(0.86)$ & $1.12(0.89)$ & $1.09(0.67)$ & $1.10(0.65)$ & $1.03(0.79)$ \\
OBF10 & $0.99(0.75)$ & $1.03(0.79)$ & $0.98(0.76)$ & $1.13(0.58)$ & $0.70(0.46)$ & $0.61(0.28)$ \\
MBF10 & $1.2(0.81)$ & $1.20(0.80)$ & $1.26(0.87)$ & $1.20(0.56)$ & $1.29(0.59)$ & $1.23(0.79)$ \\
IBF10 & $1.10(0.79)$ & $1.08(0.78)$ & $1.14(0.82)$ & $1.17(0.58)$ & $1.00(0.51)$ & $1.08(0.61)$ \\
LA10 & $0.52(0.77)$ & $0.56(0.79)$ & $0.48(0.78)$ & $0.53(0.51)$ & $0.43(0.51)$ & $0.40(0.42)$ \\
BF14 & $1.56(0.88)$ & $1.54(0.90)$ & $1.61(0.88)$ & $1.74(0.75)$ & $1.37(0.59)$ & $1.45(0.82)$ \\
OBF14 & $1.35(0.79)$ & $1.37(0.84)$ & $1.35(0.75)$ & $1.63(0.63)$ & $1.16(0.58)$ & $0.96(0.45)$ \\
BF14 & $1.9(0.85)$ & $1.87(0.87)$ & $1.91(0.87)$ & $2.16(0.72)$ & $1.52(0.50)$ & $1.63(0.76)$ \\
IBF14 & $1.46(0.76)$ & $1.42(0.77)$ & $1.52(0.76)$ & $1.84(0.61)$ & $1.39(0.49)$ & $1.34(0.61)$ \\
LA14 & $0.58(0.77)$ & $0.61(0.81)$ & $0.56(0.76)$ & $0.68(0.57)$ & $0.55(0.60)$ & $0.43(0.40)$ \\
\hline
\end{tabular}

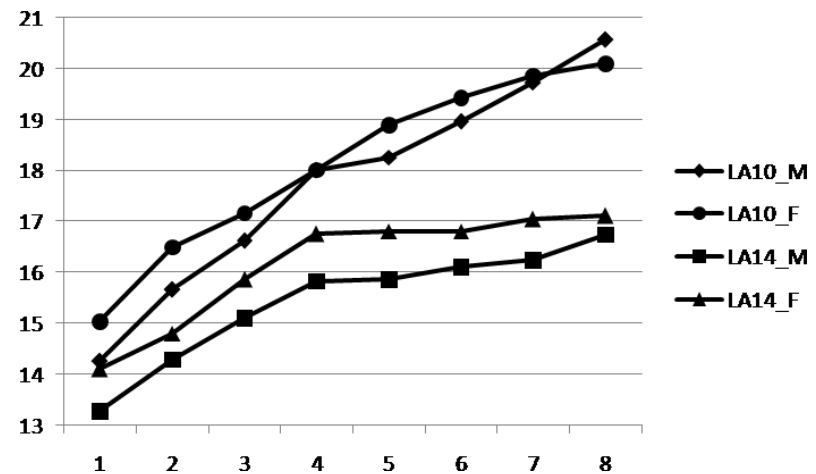

Figure 2. Changes in ultrasonic M. longissimus area as functions of scans in pigs of the Iberian breed.

These results are in line with the allometric coefficients obtained both in adipose tissue and muscle being higher in the back fat measurements. In relation to adipose tissue was the medium layer of back fat at 14th rib level with the highest growth rates and the outer back fat layer at 10th rib level with the lowest development speed. The M. longissimus area showed an allometric coefficient lower than 1 in all cases. Also, the allometric coefficients of ultrasound back fat depth measurements were slightly higher in females, while the allometric coefficients of $\mathrm{M}$. longissimus area were higher in males. Although the differences were not statistically signifi- cant $(p>0.05)$. However, in relation to the diet, the $\mathrm{C}$ group presented a higher growth level.

Correlation coefficients between ultrasound measurements at the eighth scan with corresponding measurements at the previous scan (only those that showed statistically significant values) are shown in Table 5. Positive and in most cases significant correlations were observed for the measurements assessed, except for M. longissimus area at the 10th rib, which was not significantly $(p>0.05)$ correlated with the fourth, fifth and sixth scans and was positively significantly $(p>0.05)$ correlated with the seventh scan. These coefficients ranged from 0.18 to 0.89 ( $p<0.05$ when $r \geq 0.43)$ and showed a tendency to increase this relationship as we approach the eighth scan. The correlations between M. longissimus area measurements were lower than for the other ultrasound measurements.

The $R^{2}$ values for the regression equations (Table 6) to estimate M. longissimus area were lower $(0.15$ to -0.01$)$ than the values found for the prediction of fat measurements ( 0.62 to -0.02). As the time between scans increased, the regression coefficient decreased.

\section{Discussion}

There are no previous studies on serial scans of adipose and muscular tissue during growth and the final fattening phase in adipogenetic breeds such as the Iberian pig. However, 

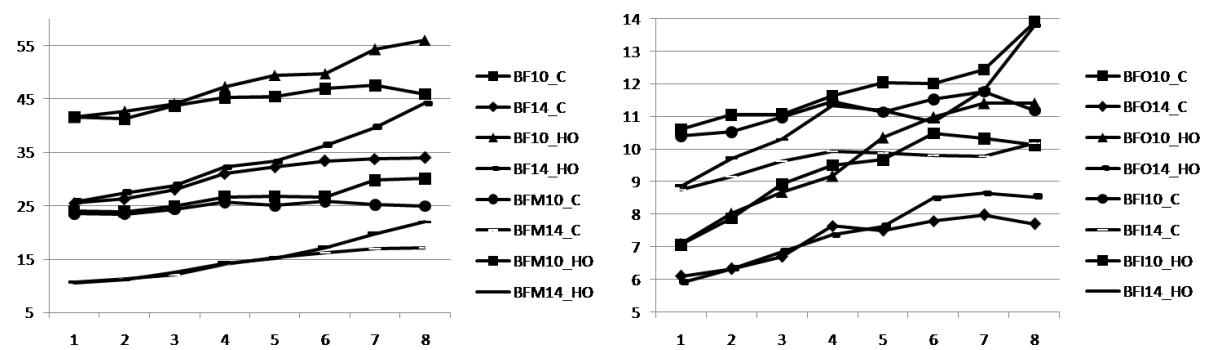

Figure 3. Changes in ultrasonic back fat depth and its layers as functions of feed in pigs of the Iberian breed.

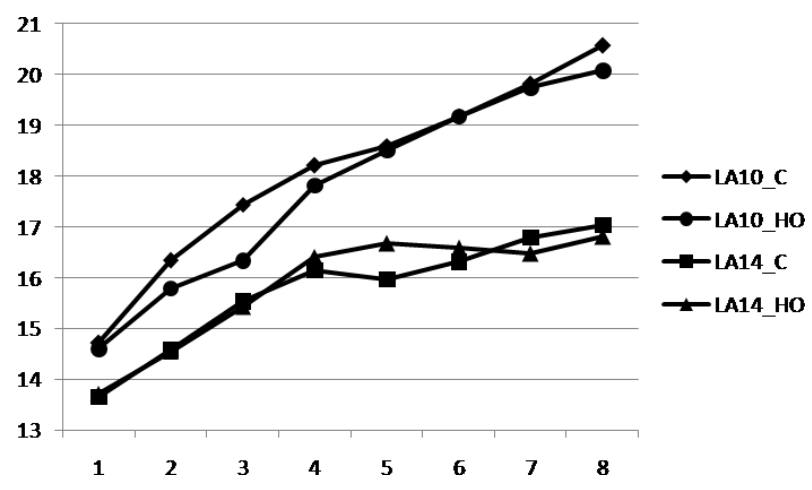

Figure 4. Changes in ultrasonic M. longissimus area as functions of feed in pigs of the Iberian breed.

Table 5. Correlation coefficients between ultrasound measurements at the eighth scan and previous scans.

\begin{tabular}{lrrrr}
\hline Scan & Seventh & Sixth & Fifth & Fourth \\
\hline BF10-8 & $0.81^{* * *}$ & $0.58^{*}$ & $0.54^{*}$ & $0.59^{*}$ \\
BFO10-8 & $0.84^{* * *}$ & $0.68^{* *}$ & $0.68^{* *}$ & $0.55^{*}$ \\
BFM10-8 & $0.80^{* * *}$ & $0.62^{* *}$ & $0.62^{* *}$ & $0.63^{* *}$ \\
BFI10-8 & $0.77^{* * *}$ & $0.55^{*}$ & $0.56^{*}$ & $0.49^{*}$ \\
LA10-8 & $0.46^{*}$ & 0.24 & 0.22 & 0.18 \\
BF14-8 & $0.82^{* *}$ & $0.67^{* *}$ & $0.57^{*}$ & $0.53^{*}$ \\
BFO14-8 & $0.82^{* * *}$ & $0.66^{* *}$ & $0.54^{*}$ & $0.45^{*}$ \\
BFM14-8 & $0.89^{* * *}$ & $0.74^{* * *}$ & $0.69^{* *}$ & $0.61^{* *}$ \\
BFI14-8 & $0.75^{* * *}$ & $0.60^{* *}$ & $0.55^{*}$ & $0.46^{*}$ \\
LA14-8 & $0.63^{* *}$ & $0.55^{*}$ & $0.43^{*}$ & $0.45^{*}$ \\
\hline
\end{tabular}

BF10-8: ultrasonic back fat depth at 10th rib in the eighth scan; BFO10-8: ultrasonic outer layer depth at 10th rib in the eighth scan; BFM10-8: ultrasonic middle layer depth at 10th rib in the eighth scan; BFI10-8: ultrasonic inner layer depth at 10th rib in the eighth scan; LA10-8: M. longissimus area at 10th rib in the eighth scan; BF14-8: ultrasonic back fat depth at 14th rib in the eighth scan; BFO14-8: ultrasonic outer layer depth at 14th rib in the eighth scan; BFM14-8: ultrasonic middle layer depth at 14th rib in the eighth scan; BFI14-8: ultrasonic inner layer depth at 14th rib in the eighth scan; LA14-8: M. longissimus area at 14 th rib in the eighth scan. ${ }^{*} p<0.05$. ** $p<0.01 .{ }^{* * *} p<0.001$.

there is consensus in the literature on the influence of breed on back fat thickness (Rybarczyk et al., 2011). Warriss et al. (1990) recorded average values of 11.0 and $23.0 \mathrm{~mm}$ in Pietrain and Large Black pigs, respectively. Also, Serrano
Table 6. Coefficients $\left(R^{2}\right)$ for the regression function relating the ultrasound measurements at the eighth scan to corresponding measurements at the previous scan.

\begin{tabular}{lrrrrrrr}
\hline Scan & First & Second & Third & Fourth & Fifth & Sixth & Seventh \\
\hline BF10_8 & -0.03 & -0.02 & 0.03 & $0.18^{* *}$ & $0.08^{*}$ & $0.24^{* * *}$ & $0.53^{* * *}$ \\
BF14_8 & -0.02 & -0.03 & 0.04 & 0.02 & -0.02 & $0.47^{* * *}$ & $0.62^{* * *}$ \\
LA10_8 & $0.09^{*}$ & 0.06 & $0.08^{*}$ & -0.01 & $0.07^{*}$ & 0.00 & -0.01 \\
LA14_8 & $0.15^{* *}$ & 0.08 & -0.01 & 0.06 & $0.10^{*}$ & 0.04 & $0.12^{* *}$ \\
\hline BF10-8: ultrasonic back fat depth at 10th rib in the eighth scan; LA10-8: M. longissimus area at 10th rib in \\
the eighth scan; BF14-8: ultrasonic back fat depth at 14th rib in the eighth scan; LA14-8: M. longissimus \\
area at 14th rib in the eighth scan. \\
${ }^{*} p<0.05 .{ }^{* *} P 0.01 .{ }^{* * *} p<0.001$.
\end{tabular}

et al. (2008) recorded values of 50, 51.1 and $80.1 \mathrm{~mm}$ for back fat thickness in Danish Duroc, Spanish Duroc and Retinto Iberian pig breeds, respectively. The means of back fat thickness at slaughter were similar to results in previous studies carried out on Iberian pigs (De Pedro, 1987; Dobao et al., 1987; Daza et al., 2005, 2006; Rey et al., 2006; Serrano et al., 2008; Ayuso et al., 2014). As expected, these values were higher than those reported for local or autochthonous breeds and improved breeds in previous studies (Minelli et al., 2013; Franco et al., 2014). The values were also higher than those reported for Celta pigs $(38.0 \pm 7.9 \mathrm{~mm}$; a Spanish native breed adapted to the extensive production system) (Temperan et al., 2014). These results are not surprising since the Iberian is a local breed from the southwestern region of Spain with a distinct adipogenetic nature and shows a high subcutaneous adiposity, contributed to by their diet because as indicated by Cunningham et al. (1973), pigs fed with a low-protein diet were fatter than pigs fed with a high-protein diet. These differences could be considered as a consequence of selection for growth efficiency of lean meat or fat. The differences between breeds for back fat thickness remained when comparing the thickness / body weight ratio $\left(\mathrm{mm} \mathrm{kg}^{-1}\right): 0.379 \mathrm{~mm} \mathrm{~kg}^{-1}$ in our study vs. 0.177 to 0.298 (Cunningham et al., 1973) or $0.271 \mathrm{~mm} \mathrm{~kg}^{-1}$ (Moeller et al., 1998). However, some local breeds have values close to those found in our study: $0.327 \mathrm{~mm} \mathrm{~kg}^{-1}$ in Nero Siciliano (Pugliese et al., 2003), $0.363 \mathrm{~mm} \mathrm{~kg}^{-1}$ in Cinta Senese (Franci et al., 2005), $0.308 \mathrm{~mm} \mathrm{~kg}^{-1}$ in Casertana, and $0.359 \mathrm{~mm} \mathrm{~kg}^{-1}$ in Mora (Fortina et al., 2005). This could be primarily due to the differences in slaughter weight, breed 
and feeding of the animals, factors that significantly influence the back fat thickness (Schinckel et al., 2002; Serrano et al., 2008).

The differences found between the back fat thickness at the 10th and 14th rib levels in our work demonstrate the lack of uniformity in the distribution of subcutaneous fat throughout the body of pigs, consistent with previous studies (Correa et al., 2006; Mas et al., 2010; Aro and Akinjokun, 2012). However, the back fat thickness at 10th rib level was higher in the first scans, but was higher at 14th rib level for the whole study period. In this regard, Fortin et al. (1980) indicated that fat over the back of the pork carcass was not evenly distributed when evaluating back fat thickness at various anatomical locations and positions. Comparison of the results of our work (Iberian pigs) with those obtained by Fortin (1986) in Yorkshire pigs clearly verifies the effect of breed (fattest vs. leanest) on back fat depth growth. In our work, we find a relative increase over live weight in back fat thickness during the control period studied $\left(0.512\right.$ and $0.279 \mathrm{~mm} \mathrm{~kg}^{-1}$ at the first and last scans, respectively), whereas Yorkshire pigs descended from 20 to $120 \mathrm{~kg}$ live weight $\left(0.51\right.$ and $0.282 \mathrm{~mm} \mathrm{~kg}^{-1}$, respectively). McKay et al. (1984) also recorded declines in dorsal fat thickness / body weight ratio between 22.5 and $90.0 \mathrm{~kg}$ of live weight in Minnesotan (0.551 to $0.413 \mathrm{~mm} \mathrm{~kg}^{-1}$ ), Pietrain $\left(0.443\right.$ to $\left.0.328 \mathrm{~mm} \mathrm{~kg}^{-1}\right)$ and Yorkshire pigs $(0.412$ to $\left.0.308 \mathrm{~mm} \mathrm{~kg}^{-1}\right)$.

The increase in back fat thickness recorded by Swantek et al. (2014) in Berkshire pigs (286.5\%) and Greer et al. (1987) in crossbreed pigs ( $250 \%$ ) was similar to that obtained in our study for BF10 (266.3\%) but much lower than the increase recorded for BF14 (409.3\%). The lowest increase recorded by Richmond and Berg (1971) in Duroc $\times$ Yorkshire, Hampshire $\times$ Yorkshire and Yorkshire $\times$ Yorkshire $(143.4 \%)$ pigs may in part be because the animals used belonged to a lean breed and also because a different weight range was considered ( $25.3 \mathrm{~kg}$ at baseline and $80.5 \mathrm{~kg}$ at the end), as was found in the work of Fortin (1980).

Subcutaneous fat tissue in pigs consists of two, and sometimes three, fat layers (Fortin, 1986). In the present study, the outer, middle and inner layers represented 21.65, 50.69 and $28.48 \%$, respectively, of the total back fat thickness. However, they differed from the results of Newcom et al. (2004), who recorded values of 50.2, 29.67 and $20.11 \%$ for the outer, middle and inner layers, respectively, in Duroc pigs and the results of Alfonso et al. (2005) in Basque pigs (33.7, 40 and $26.27 \%$, respectively). Likewise, the importance of each layer differs between studies: middle $>$ inner $>$ outer vs. outer $>$ middle $>$ inner. Meanwhile, Pugliese et al. (2003), recorded only the outer and inner layers, providing percentages of 44.94 and $55.32 \%$, respectively, in Nero Siciliano pigs, confirming the differences between breeds in this work. The differences found by Dobao et al. (1987) could be mainly due to slaughter weight (130-140 kg vs. $162 \mathrm{~kg}$ in our study). The total back fat depth also influences the percentage of each layer (Moody and Zobrisky, 1966). These authors found that increasing the total back fat thickness decreased the middle layer and increased the outer layer, as occurred in our case at 10th rib level, while at 14 th rib level the middle layer is the one that grows. The unequal rate of development of adipose layers is in agreement with Fortin (1986) and McEvoy et al. (2007).

Similarly to what was observed for back fat thickness, we check the lack of uniformity in the distribution of the different layers along the body of pigs, in line with Pugliese et al. (2003), who recorded percentages of $35.48,44.82$, and $54.51 \%$ for the outer layer and $65.52,55.18$, and $45.26 \%$ for the inner layer of back fat on the dorsal midline opposite from the first and last ribs, and over the M. Gluteus medius.

In contrast to the values reported for the back fat thickness, values of M. longissimus area recorded in our study (21.99 and $19.79 \mathrm{~cm}^{2}$, or 0.136 and $0.122 \mathrm{~cm}^{2} \mathrm{~kg}^{-1}$ for LA10 and LA14, respectively) were lower than those recorded in lean breeds (Newcom et al., 2004; Stahl and Berg, 2003; Sullivan et al., 2007; Hsu et al., 2010; Mas et al., 2010; Rybarczyk et al., 2011), both in absolute values $\left(30.3-56.7 \mathrm{~cm}^{2}\right)$ and relative to body weight $\left(0.329-0.498 \mathrm{~cm}^{2} \mathrm{~kg}^{-1}\right)$ or rate of deposition $\left(0.088 \mathrm{~cm}^{2} \mathrm{~kg}^{-1}\right.$ in our study vs. $0.304 \mathrm{~cm}^{2} \mathrm{~kg}^{-1}$ by Moeller et al. (1998). This difference may be explained in part by constant genetic improvement of this parameter.

Sex had a significant effect on back fat thickness, both overall and in each of the layers, except the inner layer of back fat, since the sexes differed significantly in distribution of back fat thickness. Females had thicker 10th and 14th rib level fat depth and bigger M. longissimus area than males. Kemster and Evans (1979) concluded that subcutaneous fat accumulated more ventrally in females and more dorsally in males. Sex differences in the present study are supported by previous reports for the effect of the sex (Serrano et al., 2008; Mas et al., 2010; Aro and Akinjokun, 2012; Minelli et al., 2013; Swantek et al., 2014; Suárez-Belloch et al., 2015). However, the differences in sex for back fat thickness were contrary to the observations of McKay et al. (1984). The higher adiposity of male carcasses resulted from the development of subcutaneous fat rather than internal fat tissue, and females having proportionally more fat depth over the shoulder and relatively less over the mid-back than males. Also, the higher fat depth in males is indicative of higher potential for fattening than females, in agreement with previous reports (Cisneros et al., 1996), which is likely related to the higher voluntary feed intake of males. Generally, females were leaner than males based on greater values for M. longissimus area, along with less back fat. However, in our study males were leaner than females and we did not find significant differences in M. longissimus area possibly because the animals were castrated. The effects of sex were probably reduced by castration of both males and females, as reported by Mayoral et al. (1999) for castrated male and female Iberian pigs. 
Diet had significant effects on the back fat thickness, both overall and for each layer, while M. longissimus area was not affected by this factor, in agreement with Rey et al. (2006). Pigs fed a HO diet had significantly higher $(p<0.05)$ values for the total back fat thickness when compared with the group fed with the $\mathrm{C}$ diet. These results could be due in part to the growth rate, higher in the HO group, which suggests that the faster growth was a fatter growth, in agreement with Pugliese et al. (2003) and Millet et al. (2004). In contrast, Ayuso et al. (2014) indicated that Montanera animals showed similar back fat thickness compared to the high-oleic group, although the values were higher in the group fed a diet high in oleic; the M. longissimus area between those two groups was statistically different. Also, Martin et al. (2008), Guillevic et al. (2009) and Mas et al. (2010) working with crossbred pigs found no differences between swine fed elevated levels of monounsaturated fat and control animals for first-rib fat thickness and $\mathrm{M}$. longissimus area.

The outer, middle and inner back fat layers measured at two locations (10th and 14th rib level) followed the same trend as the back fat thickness and showed significant $(p<$ 0.05 ) differences between feeding systems. Conversely, in the inner back fat layer more marked effects than those observed in the total back fat, outer and middle layers were detected. These results could indicate that the outer and middle layers tended to have a more constant fat deposition when compared with the inner layer. Wood et al. (1975) in previous research found that the rate at which cell diameter increased in size with increasing live weight was greater in the inner layer than in the other layers.

The allometric coefficients of back fat depth in relation to live weight allow one to better understand its evolution with growth. The isauxesis is condition of a linear measurement with respect to another of third degree, such as live weight, and is expressed by the allometric coefficient of 0.333 (Walstra, 1980) instead of unity. Lower or higher coefficients indicate slower or faster relative growth, respectively. The back fat development and its layers both in castrated Iberian male pigs and spayed Iberian female pigs showed differences through allometric coefficients. Each differential value could be interpreted as a different rate of maturation in tissue. Also, Wood et al. (1978) found different grades of back fat layer development and Mersmann (1982) evaluated the back fat development by ultrasound technique in different points of spin, concluding that the growth was not homogeneous.

The three back fat layers have distinct patterns of growth and should be considered as three separate tissues (Fortin, 1986). At birth, the outer layer is predominant. Then, at a given time during growth, the middle layer, due to a faster rate of development, becomes thicker. Finally, at a later stage, the inner layer begins to develop (Fortin, 1986). Fortin (1986) and Schinckel et al. (2002) indicated that, at light weights, the outer layer was usually more predominant, whereas, at heavier weights, the middle layer became predominant. In our study, the middle layer was predominant throughout the study period because the study began when the animals had a live weight of $64 \mathrm{~kg}$.

Consistent with Fortin (1986) and Schinckel et al. (2002), in our study the allometric coefficients for the outer layer thickness of back fat $(b=1.13)$ were of lower magnitude than the middle layer thickness of back fat $(b=1.20)$. Contrary to the conclusions of Mersmann (1982) and according with Fortin (1986), the growth of the inner layer was intermediate between the outer and the middle. These results agree with those of McMeekan (1940), Sink and Miller (1962), and Sink et al. (1964), who reported that the inner (second) layer increased faster and had a greater thickness than the outer (first) layer as total back fat increased. Also, McEvoy et al. (2007) indicated that the change in thickness per unit change in body weight is greatest in the middle layer followed by the outer and inner layers.

The inner layer development is especially interesting because there are previous studies (Newcom et al., 2005; Ayuso et al., 2012) that relate thickness with a higher fat infiltration. We found remarkable differences in the allometric coefficient of the inner layer between the 10th and 14th rib levels. Thus, the level at which the measurement is recorded is important.

The M. longissimus area presented an allometric coefficient lower than 1, presenting a negative growth level of lean tissue as the fattening phase increased. This is in accordance with Virgili et al. (2003), who reported a decrease in lean yield of the loin from 143 to $183 \mathrm{~kg}$ live weight pigs and with Courchaine et al. (1996), who found that as age and body weight increased lean meat percentage decreased.

The Pearson correlation coefficients between ultrasound measurements at the fourth, fifth, sixth and seventh scans with the corresponding ultrasound measurements at the eighth scan ranged from 0.53 to 0.82 for back fat thickness and from 0.18 to 0.63 for M. longissimus area. These results were similar to those obtained by Tyra et al. (2001) in Polish Large White, Polish Landrace, Pietrain and Duroc breeds ( $r=0.567-0.635$ and $r=0.552$ for back fat and loin area measurements, respectively) and higher than those recorded by Courchaine et al. (1999) in Yorkshire and crossbred pigs ( $r=0.639$ and $r=0.453$, respectively), with initial and final average weights of 68.3 and $109.8 \mathrm{~kg}$, respectively. As in the works cited, in our study the correlation coefficients between the traits of back fat thickness were greater than those obtained for the M. longissimus area. Robinson et al. (1987) recorded a correlation of 0.65 between ultrasound back fat at 17 and 20 weeks of age, and McLaren et al. (1989) reported moderate to high correlations of live animal ultrasound back fat measured throughout the nursery, grower and finisher stages to carcass back fat at slaughter. In line with the results of previous work on Iberian pigs (Ayuso et al., 2013), the highest correlation coefficients were recorded for the middle layer, followed by the outer and inner layers. This could be attributed, as indicated by these authors, to the lower accuracy in the measurement of the inner layer depth due to a wide variation in loin shape. As in the study of Kol- 
stad et al. (1996), correlation coefficients decreased with increasing intervals between scans. Regression resulted as expected, thus corroborating the correlation results. Consistent with the results obtained by Courchaine et al. (1999) in Yorkshire barrows and Ayuso et al. (2012) in Iberian pigs, the regression coefficients for back fat measurements were higher than those obtained for M. longissimus area. However, the regression coefficients obtained from measurements taken between the seventh and eighth scans were higher than the regression coefficients between carcass and ultrasonic measurements for back fat layer variables and $\mathrm{M}$. longissimus area at two anatomical locations obtained by the aforementioned authors in Iberian pigs.

\section{Conclusions}

The relative back fat growth was higher than M. longissimus area, not permitting the establishment of a similar growth pattern for fat and muscle. Also, the sex and diet must be taken into account in predictive models. The subcutaneous adipose layers in Iberian pigs grow at different rates during the last 6 months before slaughter, with the ultrasound serial scan it is possible to show these changes.

The changes in diet, in the fat development and the sex affect the adipose tissue development, being more noticeable in the middle layer of back fat at 10th rib level and the inner layer at 14th rib level. However, the use of an enriched oleic acid diet and the sex do not affect loin development.

As the middle layer of back fat shows more growth, this layer could be the best to be included in predictive models.

Back fat thickness at the eighth scan could be predicted with moderate accuracy from corresponding measurements taken 30 days earlier and with less accuracy as the interval between measurements increases. The M. longissimus area at the eighth scan can also be predicted, but with less accuracy.

Data availability. No data sets were used in this article.

Competing interests. The authors declare that they have no conflict of interest.

Acknowledgements. This research was supported by INIA RTA 2007-000-93-00-00 and FEDER.

Edited by: Steffen Maak

Reviewed by: two anonymous referees

\section{References}

Alfonso, L., Mourot, J., Insausti, K., Mendizabal, J. A., and Arana, A.: Comparative description of growth, fat deposition, carcass and meat quality characteristics of Basque and Large White pigs, Anim. Res., 54, 33-42, 2005.

Aro, S. O. and Akinjokun, O. M.: Meat and carcass characteristics of growing pigs fed microbially enhanced cassava peel diets, Arch. Zootec., 61, 407-414, 2012.

Ayuso, D., Izquierdo, M., Hernández, F. I., Bazán, J., and Corral, J. M.: Ultrasonographic in vivo estimation of back fat depth and Longissimus dorsi area in Iberian pigs, in: 7th International Symposium on the Mediterranean Pig Zaragoza: CIHEA M, edited by: De Pedro, E. J., CABe, 309-313, 2012.

Ayuso, D., González, A., Hernández, F., Corral, J. M., and Izquierdo, M.: Prediction of carcass composition, ham and foreleg weights, and lean meat yields of Iberian pigs using ultrasound measurements in live animals, J. Anim. Sci., 91, 18841892, https://doi.org/10.2527/jas.2012-5357, 2013.

Ayuso, D., González, A., Hernández, F., Peña, F., and Izquierdo, M.: Effect of sex and final fattening on ultrasound and carcass traits in Iberian pigs, Meat. Sci., 96, 562-567, 2014.

BOE: REAL DECRETO 1469/2007, de 2 de noviembre, por el que se aprueba la norma de calidad para la carne, el jamón, la paleta y la caña de lomo ibéricos, Madrid, Spain, 45087-45104, 2007.

BOE: Real Decreto 4/2014, de 10 de enero, por el que se aprueba la norma de calidad para la carne, el jamón, la paleta y la caña de lomo ibérico, in: Ministerio de Agricultura ayMA (ed). Ministerio de Agricultura, alimentacion y Medio Ambiente edn, 2014.

Cisneros, F., Ellis, M., McKeith, F. K., McCaw, J., and Fernando, R. L.: Influence of slaughter weight on growth and carcass characteristics, commercial cutting and curing yields, and meat quality of barrows and gilts from two genotypes, J. Anim. Sci., 925933, 1996.

Correa, J. A., Faucitano, L., Laforest, J. P., Rivest, J., Marcoux, M., and Gariépy, C.: Effects of slaughter weight on carcass composition and meat quality in pigs of two different growth rates, Meat. Sci., 72, 91-99, https://doi.org/10.1016/j.meatsci.2005.06.006, 2006.

Courchaine, J. K., Jones, R. D., Gasa, J., and Azain, M. J.: Use of real-time ultrasound in pigs during the early finishing phase to predict carcass composition at slaughter, The Professional Animal Scientist, 15, 100-105, https://doi.org/10.15232/S10807446(15)31736-8, 1999.

Cunningham, P. J., Socha, T. E., Peo, E. R., and Mandigo, R. W.: Gain, feed conversion and carcass traits of swine fed under two nutritional regimes, J. Anim. Sci., 37, 75-80, 1973.

Daza, A., Mateos, A., Rey, A. I., and López-Bote, C. J.: Feeding level in the period previous to the late fattening phase influences fat composition at slaughter in free-ranged Iberian pigs, Arch. Anim. Nutr., 59, 227-236, 2005.

Daza, A., Mateos, A., Carrasco, C. L., Rey, A., Ovejero, I., and López-Bote, C. J.: Effect of feeding system on the growth and carcass characteristics of Iberian pigs, and the use of ultrasound to estimate yields of joints, Meat. Sci., 72, 1-8, 2006.

De Pedro, E.: Estudio de los factores sexo y peso de sacrificio sobre las características de la canal del cerdo Ibérico, Cordoba, $\mathrm{PhD}$ Thesis, University of Cordoba, Spain, 181 pp., 1987. 
Dobao, M. T., Rodrigañez, J., Silio, L., Toro, M. A., de Pedro, E., and Garcia de Siles, J. L.: Crecimiento y caracterisitcas de canal en cerdos Ibéricos, Duros-Jersey x Ibérico y Jianxing x Ibérico, Investigación Agraria Producción y Sanidad Animales, 2, 9-23, 1987.

Dourmad, J., Etienne, M., and Noblet, J.: Measuring backfat depth in sows to optimize feeding strategy, INRA Prod. Anim., 14, 4150, 2001.

Fernández, A., De Pedro, E., Núñez, N., Silió, L., García-Casco, J., and Rodríguez, C.: Genetic parameters for meat and fat quality and carcass composition traits in Iberian pigs, Meat. Sci., 64, 405-410, 2003.

Fortin, A.: The effect of slaughter weight on the carcass characteristics of Yorkshire barrows and gilts, Can. J. Anim. Sci., 60, 265-274, 1980.

Fortin, A.: Development of backfat and individual fat layers in the pig and its relationship with carcass lean, Meat. Sci., 18, 255270, https://doi.org/10.1016/0309-1740(86)90016-1, 1986.

Fortin, A., Sim, D. W., and Talbot, S.: Ultrasonic measurements of backfat thickness at different locations and positions on the warm pork carcass and comparisons of ruler and ultrasonic procedures, Can. J. Anim. Sci., 60, 635-641, 1980.

Fortina, R., Barbera, S., Lussiana, C., Mimosi, A., Tassone, S., Rossi, A., and Zanardi, E.: Performances and meat quality of two Italian pig breeds fed diets for commercial hybrids, Meat. Sci., 71, 713-718, https://doi.org/10.1016/j.meatsci.2005.05.016, 2005.

Franci, O., Bozzi, R., Pugliese, C., Acciaioli, A., Campodoni, G., and Gandini, G.: Performance of Cinta Senese pigs and their crosses with Large White, 1 Muscle and subcutaneous fat characteristics, Meat. Sci., 69, 545-550, https://doi.org/10.1016/j.meatsci.2004.10.005, 2005.

Franco, D., Vazquez, J. A., and Lorenzo, J. M.: Growth performance, carcass and meat quality of the Celta pig crossbred with Duroc, and Landrance genotypes, Meat. Sci., 96, 195-202, https://doi.org/10.1016/j.meatsci.2013.06.024, 2014.

Greer, E. B., Lowe, T. W., and Giles, L. R.: Comparison of ultrasonic measurement of backfat depth on live pigs and carcases with a digital recording instrument, Meat. Sci., 19, 111-120, https://doi.org/10.1016/0309-1740(87)90016-7, 1987.

Guillevic, M., Kouba, M., and Mourot, J.: Effect of a linseed diet or a sunflower diet on performances, fatty acid composition, lipogenic enzyme activities and stearoyl-CoAdesaturase activity in the pig, Livest. Sci., 124, 288-294, https://doi.org/10.1016/j.livsci.2009.02.009, 2009.

Hsu, W. L., Johnson, R. K., and van Vleck, L. D.: Effect of pen mates on growth, backfat depth, and longissimus muscle area of swine, J. Anim. Sci., 88, 895-902, https://doi.org/10.2527/jas.2009-1879, 2010.

Kempster, A. J.: Fat partition and distribution in the carcass of cattle, sheep and pigs: a review, Meat. Sci., 5, 83-98, 1980.

Kempster, A. J. and Evans, D. G.: A comparison of different predictors of the lean content of pig carcasses, 1. Predictors for use in commerical classification and grading, Anim. Prod., 28, 87-96, 1979.

Kolstad, K., Jopson, N. B., and Vangen, O.: Breed and sex differences in fat distribution and mobilization in growing pigs fed at maintenance, Livest. Prod. Sci., 47, 33-41, https://doi.org/10.1016/s0301-6226(96)01001-9, 1996.
Lopez-Bote, C. J.: Sustained utilization of the Iberian pig breed, Meat. Sci., 49, S17-S27, 1998.

Martin, D., Muriel, E., Gonzalez, E., Viguera, J., and Ruiz Carrascal, J.: Effect of dietary conjugated linoleic acid and monounsaturated fatty acids on productive, carcass and meat quality traits of pigs, Livest. Sci., 117, 155-164, 2008.

Mas, G., Llavall, M., Coll, D., Roca, R., Diaz, I., Gispert, M., Oliver, M. A., and Realini, C. E.: Carcass and meat quality characteristics and fatty acid composition of tissues from Pietrain-crossed barrows and gilts fed an elevated monounsaturated fat diet, Meat. Sci., 85, 707-714, https://doi.org/10.1016/j.meatsci.2010.03.028, 2010.

Mayoral, A. I., Dorado, M., Guillén, M. T., Robina, A., Vivo, J. M., Vazquez, C., and Ruiz, J.: Development of meat and carcass quality characteristics in Iberian pigs reared outdoors, Meat. Sci., 52, 315-324, 1999.

McEvoy, F. J., Strathe, A. B., Madsen, M. T., and Svalastoga, E.: Changes in the relative thickness of individual subcutaneous adipose tissue layers in growing pigs, ACTA Vet. Scand., 49, https://doi.org/10.1186/1751-0147-49-32, 2007.

McKay, R. M., Rempel, W. E., Cornelius, S. G., and Allen, C. E.: Differences in carcass traits of three breeds of swine and crosses at five stages of development, Can. J. Anim. Sci., 64, 293-304, 1984.

McLaren, D. G., McKeith, F. M., and Novakofski, J.: Prediction of carcass characteristics at market weight from serial real-time ultrasound measures of backfat and loin eye area in the growing pig, J. Anim. Sci., 67, 1657-1667, 1989.

McMeekan, C. P.: Growth and development in the pig with special reference to carcass quality characters, J. Agr. Sci., 30, 511-569, https://doi.org/10.1017/S002185960004822X, 1940.

Mersmann, H. J.: Ultrasonic determination of backfat depth and loin area in swine, J. Anim. Sci., 54, 268-275, 1982.

Millet, S., Hesta, M., Seynaeve, M., Ongenae, E., De Smet, S., Debraekeleer, J., and Janssens, G. P. J.: Performance, meat and carcass traits of fattening pigs with organic versus conventional housing and nutrition, Livest. Prod. Sci., 87, 109-119, https://doi.org/10.1016/j.livprodsci.2003.10.001, 2004.

Minelli, G., Macchioni, P., Ielo, M. C., Santoro, P., and lo Fiego, D. P.: Effects of dietary level of pantothenic acid and sex on carcass, meat quality traits and fatty acid composition of thigh subcutaneous adipose tissue in Italian heavy pigs, Ital. J. Anim. Sci., 12, 329-336, https://doi.org/10.4081/ijas.2013.e52, 2013.

Moeller, S. J., Christian, L. L., and Goodwin, R. N.: Development of adjustment factors for backfat and loin muscle area from serial real-time ultrasonic measurements on purebred lines of swine, J. Anim. Sci., 76, 2008-2016, 1998.

Moody, W. G. and Zobrisky, S. E.: Study of backfat layers of swine, J. Anim. Sci., 25, 809-813, 1966.

Newcom, D. W., Baas, T. J., Schwab, C. R., and Stalder, K. J.: Relationship between backfat depth and its individual layers and intramuscular fat percentage in swine, Animal Industry Report, ASL R1944, AS 650 p., 2004.

Newcom, D. W., Baas, T. J., Schwab, C. R, and Stalder, K. J.: Genetic and phenotypic relationships between individual subcutaneous backfat layers and percentage of longissimus intramuscular fat in Duroc swine, J. Anim. Sci., 83, 316-323, 2005.

Pugliese, C., Madonia, G., Chiofalo, V., Margiotta, S., Acciaioli, A., and Gandini, G.: Comparison of the performances of Nero 
Siciliano pigs reared indoors and outdoors, 1 . Growth and carcass composition, Meat. Sci., 65, 825-831, 2003.

Rey, A. I., Daza, A., López-Carrasco, C., and López-Bote, C. J.: Feeding Iberian pigs with acorns and grass in either free-range or confinement affects the carcass characteristics and fatty acids and tocopherols accumulation in Longissimus dorsi muscle and backfat, Meat. Sci., 73, 66-74, 2006.

Richmond, R. J. and Berg, R. T.: Tissue development in swine as influenced by liveweight, breed, sex and ration, Can. J. Anim. Sci., 51, 31-40, 1971.

Robinson, T. F., Orme, L. E., and Park, R. L.: Growth characteristics of immature swine as determined by real-time linear array ultrasound, ASAS WS. P., 151, 1987.

Rybarczyk, A., Pietruszka, A., Jacyno, E., and Dvořák, J.: Carcass and meat quality traits of pig reciprocal crosses with a share of Pietrain breed, Czech. J. Anim. Sci., 56, 47-52, 2011.

Sather, A., Bailey, D., and Jones, S.: Real-time ultrasound image analysis for the estimation of carcass yield and pork quality, Can. J. Anim. Sci., 76, 55-62, 1996.

Schinckel, A. P., Mills, S. E., Weber, T. E., and Eggert, J. M.: A review of genetic and nutritional factors affecting fat quality and belly firmness, Proc. Natl. Swine Imp. Fed. Conf. Nashville, TN, available at: http://www.nsif.com/Conferences/ 2002/reviewgeneticnutritionalfactors.htm, 2002.

Serrano, M. P., Valencia, D. G., Nieto, M., Lázaro, R., and Mateos, G. G.: Influence of sex and terminal sire line on performance and carcass and meat quality of Iberian pigs reared under intensive production systems, Meat. Sci., 78, 420-428, 2008.

Sink, J. D. and Miller, R. C.: Fat deposition in swine, J. Anim. Sci., 21, 985, 1962.

Sink, J. D., Watkins, J. L., Ziegler, J. H., and Miller, R. C.: Analysis of fat deposition in swine by gas-liquid chromatography, J. Anim. Sci., 23, 121, 1964.

Stahl, C. A. and Berg, E. P.: Growth parameters and meat quality of finishing hogs supplemented with creatine monohydrate and a high glycemic carbohydrate for the last, 30 days of production, Meat. Sci., 64, 169-174, https://doi.org/10.1016/s03091740(02)00176-6, 2003.

Suárez-Belloch, J., Guada, J. A., and Latorre, M. A.: The effect of lysine restriction during grower period on productive performance, serum metabolites and fatness of heavy barrows and gilts, Livest. Sci., 171, 36-43, https://doi.org/10.1016/j.livsci.2014.11.006, 2015.
Sullivan, Z. M., Honeyman, M. S., Gibson, L. R., and Prusa, K. J.: Effects of triticale-based diets on finishing pig performance and pork quality in deep-bedded hoop barns, Meat. Sci., 76, 428-437, https://doi.org/10.1016/j.meatsci.2006.12.002, 2007.

Swantek, P. M., Roush, W. B., Stender, D. R., Mabry, J. W., and Honeyman, M. S.: Backfat Depth and Loin Eye Area Measurements of Purebred Berkshire Pigs Housed in Hoop Buildings in Iowa, Animal Industry Report, available at: http://lib.dr.iastate. edu/ans_air/vol660/iss1/101, ASL R2936, AS 660 p., 2014.

Temperan, S., Lorenzo, J. M., Castiñeiras, B. D., Franco, I., and Carballo, J.: Carcass and meat quality traits of celta heavy pigs, Effect of the inclusion of chestnuts in the finishing diet, Span. J. Agric. Res., 12, 694-707, https://doi.org/10.5424/sjar/20141235057, 2014.

Tyra, M., Szyndler-Nedza, M., and Eckert, R.: Possibilities of using ultrasonography in breeding work with pigs. Part II - Relationships between measurements obtained by different techniques and detailed dissection results, Ann. Anim. Sci., 11, 193-205, 2011.

Virgili, R., Degni, M., Schivazappa, C., Faeti, V., Poletti, E., Marchetto, G., Pacchioli, M. T., and Mordenti, A.: Effect of age at slaughter on carcass traits and meat quality of Italian heavy pigs, J. Anim. Sci., 81, 2448-2456, 2003.

Walstra, P.: Growth and carcass composition from birth to maturityin relation to feeding level and sex in Dutch Landrace pigs, $\mathrm{PhD}$ Thesis, Agricultural University of Wageningen, the Netherlands, 207 pp., 1980.

Warriss, P. D., Brown, S. N., Franklin, J. G., and Kestin, S. C.: The thickness and quality of backfat in various pig breeds and their relationship to intramuscular fat and the setting of joints from the carcasses, Meat. Sci., 28, 21-29, https://doi.org/10.1016/03091740(90)90017-z, 1990.

Wood, J. D., Enser, M. B., and Restall, D. J.: Fat cell size in Pietrain and Large White pigs, J. Agr. Sci., 84, 221-225, 1975.

Wood, J. D., Enser, M. B., Macfie, H. J., Smith, W. C., Chadwick, J. P., Ellis, M., and Laird, R.: Fatty acid composition of backfat in Large White pigs selected for low backfat thickness, Meat. Sci., 2, 289-300, 1978. 